\title{
BIOLOGIA DE Doru luteipes (SCUDDER) E SUA CAPACIDADE PREDATÓRIA DE OVOS DE Helicoverpa zea (BODDIE)
}

\author{
Ivan Cruz ${ }^{1}$, Clarice D. Alvarenga ${ }^{2}$ e Pedro E.F. Figueiredo ${ }^{1}$
}

\begin{abstract}
Biology and Predation of Doru luteipes (Scudder) on Eggs of Helicoverpa zea (Boddie)

Laboratory studies were conducted on the biology and on the capacity of predation of Doru luteipes (Scudder) on corn earworm Helicoverpa zea (Boddie) eggs. Nymphs one day old and adults were individually placed in a Petri dish and fed corn earworm eggs. The incubation period was 7.6 days. The nymphal period (four instars) lasted 34.4 days. The total life cycle (egg-adult) took 217.9 days. The pre-oviposition period lasted 30.7 days, with females laying eggs more than once, even without been copulated. The number of eggs per female was 15.9 with a viability of $85.2 \%$. Adult longevity was 175.9 days. On average one nymph consumed 23.7 eggs per day, with a total of 812.9 eggs during this phase. Adult consumed 7457 eggs (daily consumption of 42.1 eggs) during the lifespan. In general, $8276 \mathrm{H}$. zea eggs were consumed by a single predator during total life ( 39 eggs/day).
\end{abstract}

KEY WORDS: Insecta, biological control, predator, Dermaptera, earwig.

\section{RESUMO}

O objetivo deste trabalho foi estudar a biologia e o potencial de Doru luteipes (Scudder) em laboratório, como predador de ovos de Helicoverpa zea(Boddie). Ninfas de um dia de idade e adultos foram individualizados em placas de Petri, receberam como alimento, ovos de $\mathrm{H}$. zea. O período de incubação foi, em média, 7,6 dias. O período ninfal (quatro ínstares) foi de 34,4 dias. Ociclo total do inseto foi, em média, 217,9 dias. O período pré-reprodutivo foi, em média, 30,7 dias, sendo que as fêmeas ovipositaram mais de uma vez, mesmo quando não fecundadas. O número de ovos por postura foi de 15,9 , com a viabilidade chegando a $85,2 \%$. A longevidade média do adulto, foi de 175,9 dias. Em média uma ninfa consumiu 23,7 ovos de $H$. zea por dia, num total de 812,9 ovos durante esta fase. Já o adulto do predador consumiu 7457,4 ovos, com média diária de 42,1 ovos. No geral, um predador se alimentou durante sua vida, de aproximadamente 8276 ovos de $H$. zea (39 ovos/dia).

PALAVRAS-CHAVE: Insecta, controle biológico, predador, Dermaptera.

Recebido em 26/04/94. Aceito em 16/05/95.

${ }^{1}$ CNPMS/EMBRAPA, Caixa postal 151, 35701-970, Sete Lagoas, MG.

${ }^{2}$ EPAMIG, Caixa postal 12, 39440-000, Janaúba, MG. 


\section{INTRODUÇÃO}

A lagarta-da-espiga do milho, Helicoverpa zea (Boddie) causa prejuízo à cultura do milho pela alimentação dos estilo-estigmas impedindo a fertilizaçãoe, consequentemente a formação dos grãos. Além do prejuízo direto, seu ataque pode também causar o apodrecimento dos grãos, além de favorecer a penetração de microorganismos e infestação de outras pragas como Sitophilus zeamais (Mots.) e Sitotroga cerealella (Oliv.) (Cruz et al. 1986). O controle tornase difícil, pois a praga se encontra no interior da espiga e isto resulta num controle químico ineficiente. Há também o problema do resíduo, principalmente para o milho para consumo "in natura". O controle biológico desta praga seria, portanto, altamente desejável.

O predador Doru luteipes (Scudder), vulgarmente conhecido como "tesourinha", tem mostrado ser eficiente no controle de Spodoptera frugiperda (Smith) (Reis et al. 1988) e do pulgão-verde, Schizaphisgraminum (Rond.) em sorgo(Alvarenga 1992). Oinsetoé encontrado no campo durante o ano todo, principalmente na fase inicial da cultura do milho (Cruz 1990). Observa-se, também, ocorrência do predador nas espigas e pendões do milho, suspeitando-se que possam estar se alimentando de ovos e/ou lagarta de H. zea. Em condições de campo, sua postura é realizada tanto no cartucho do milho, como na espiga, mesmo habitat da lagarta-docartucho e da lagarta-da-espiga, respectivamente (Cruz 1990). Além disso, o inseto apresenta um ciclo de vida muito longo (média de 128,5 dias, quando alimentado com ovos de $S$. frugiperda (Reis et al. 1988)), se alimentando o tempo todo, aumentando assim sua eficiência. Sua ocorrência já foi relatada na Argentina, Peru, Bolívia, Colômbia, Suriname, Guatemala e Brasil (Painter 1955, Brindle 1971, Reis et al. 1988).

A biologia e o potencial de $D$. luteipes no controle de $S$. frugiperda foram estudados por Reis et al. (1988). Estes autores observaram que as posturas do predador têm, em média, 27 ovos, colocados em agrupamentos, sem forma definida. O período de incubação é, em média, de 7,3 dias. O período ninfal possui quatro ínstares e dura, em média, 44 dias; a fase adulta é mais longa, tendo sido observados, em laboratório, insetos que viveram por mais de 300 dias. Em relação à taxa de predação foi verificado um consumo diário médio, na fase ninfal, de 12 lagartas ( $1^{\circ}$ ínstar). Na fase adulta, o inseto consumiu, em média, 21 lagartas por dia. $\mathrm{O}$ consumo de ovos, na fase ninfal, foi de 13 por dia, não tendo sido avaliado o consumo pelos adultos.

Este predador demonstrou também capacidade de controlar populações de $S$. graminum (ninfas e adultos) em sorgo (Alvarenga \& Cruz 1989) e de Heliothis spp. em algodão (Campos \& Gravena 1984). Painter (1955) sugeriu que o inseto poderia ser predador de Diatraea saccharalis (Fabricius) em milho na Guatemala. Uma outra espécie do mesmo gênero, a tesourinha $D$. taeniatum (Dohm) foi considerada como importante inimigo natural de $S$. frugiperda, na América Central (Van Huis, citado por Jones et al. 1987). Esta tesourinha, no campo, alimenta-se de ovos e pequenas lagartas da praga e pode ocorrer em altas densidades por planta. Leite \& Lara (1985), verificando a flutuação populacional dos insetos e inimigos naturais, associados a cultura da soja em Jaboticabal, SP, notaram que $D$. lineare destacouse como o predador mais abundante e que este ocorreu principalmente no início da fase de florescimento.

Oobjetivo deste trabalho foi conhecer a biologia e o potencial de $D$. luteipes como predador de ovos de H. zea, em condições de laboratório. 


\section{MATERIAL E MÉTODOS}

O trabalho foi conduzido no laboratório de criação de insetos da EMBRAPA/Centro Nacional de Pesquisa de Milho e Sorgo, em Sete Lagoas, MG, à temperatura de $25 \pm 1{ }^{\circ} \mathrm{C}$, UR $70 \pm 10 \%$ e fotofase de 12 horas. Ninfas de um dia de idade, provenientes da criação estoque mantida no CNPMS foram individualizadas em placas de Petri contendo ovos de $H$. zea inviabilizados por lâmpada germicida, e um pedaço de algodão embebido em água, para simular umidade e satisfazer os hábitos de tigmotropismo positivo do inseto(Lima 1938). Para obtenção de posturas e eclosão de ninfas em laboratório, foram obtidos 12 casais da criação mantida em cartuchos de milho com ovos de $H$. zea. Os casais foram individualizados, assim que se transformaram em adultos, em placas de Petri contendo um pedaço de algodão molhado e ovos de H. zea como alimento.

Foram avaliados os seguintes aspectos biológicos do inseto: período de incubação, viabilidade dos ovos, número e duração de ínstares, período de pré-oviposição, longevidade de adultos e o potencial do inseto como predador, através da contagem diária de ovos consumidos.

\section{RESULTADOS E DISCUSSÃO}

Parâmetros Biológicos de $D$. luteipes. O período de incubação de $D$. luteipes foi, em média, de 7,6 dias, aproximando-se do encontrado por Reis et al. (1988) que foi de 7,3 dias, quando o predador foi criado com ovos de $S$. frugiperda. O período ninfal foi de 34,4 dias, em média, apresentando quatro ínstares, com exceção de um indivíduo, que apresentou cinco ínstares (Tabela 1).

O período pré-reprodutivo foi de 30,7 dias, em média, podendo chegar até a 57 dias. Foi observado que as fêmeas ovipositaram mais de uma vez, mesmo quando não fecundadas. $O$

Tabela 1. Aspectos biológicos de Doru luteipes criada com ovos de Helicoverpa zea, em laboratório em condições de temperatura $\left(25 \pm 1^{\circ} \mathrm{C}\right)$, umidade relativa $(70 \pm 10 \%)$ e fotofase $(12 \mathrm{~h})$.

\begin{tabular}{lcc}
\hline Parâmetros & Média \pm Erro padrão & $N^{\circ}$ de observações \\
\hline Período de incubação (dias) & $7,6 \pm 0,21$ & 25 \\
Período ninfal (dias) & $34,4 \pm 0,54$ & 65 \\
Longevidade do adulto (dias) & $175,9 \pm 11,54$ & 38 \\
Ciclo total (dias) & $217,9 \pm 11,24$ & 38 \\
Período pré-reprodutivo (dias) & $30,7 \pm 4,15$ & 12 \\
Número ovos/postura & $15,9 \pm 1,20$ & 29 \\
Viabilidade dos ovos (\%) & 36,5 & 12 \\
Fêmea com macho & 85,2 & 17 \\
Fêmea sem macho & & \\
\hline
\end{tabular}


mesmo foi observado por Reis et al. (1988) que obtiveram períodos pré-reprodutivos menores para a tesourinha alimentada com ovos de $S$. frugiperda (18,6 dias, em média). $O$ número de ovos por postura foi de 15,9, menor que o encontrado por Reis et al. (1988) (26,6 ovos por postura). A viabilidade dos ovos variou em função da presença ou ausência do macho, sendo que no primeiro caso, esta foi menor, observando-se somente $36,5 \%$, enquanto na ausência do macho a viabilidade foi, em média, $85,2 \%$. Esta variação, se deve, provavelmente, ao fato de, no primeiro caso, o macho perturbar a fêmea e consequentemente esta se alimentar dos próprios ovos para preservá-los. Foram observados adultos com até 308 dias, atingindo, no entanto, uma longevidade média de 175,9 dias. O ciclo total do inseto, foi, em média, de 217,9 dias, sendo que alguns insetos viveram por quase um ano (343 dias).

Capacidade Predatória de $\boldsymbol{D}$. luteipes. Notou-se um consumo crescente de ovos de $H$. zea do primeiro ao último ínstar, podendo ser observado um aumento de aproximadamente duas vezes a cada ínstar. Somente entre o quatro e o quinto ínstares não foi registrado este aumento no consumo, lembrando, no entanto, que este fato só ocorreu em um indivíduo (Tabela 2). Observou-se que a duração de cada ínstar não variou muito, ficando aproximadamente entre oito a 10 dias. O número de ovos consumidos por dia por tesourinha em cada ínstar, foi de 4,6 no primeiro ínstar chegando até 45,3 ovos no quarto ínstar, totalizando 434,5 ovos consumidos pela tesourinha neste ínstar.

Tabela 2. Consumo total e diário de Helicoverpa zea por Doru luteipes, durante a fase ninfal e duração de cada ínstar, em laboratório sob condições controladas de temperatura (25 $\left.\pm 1^{\circ} \mathrm{C}\right)$, umidade relativa $(70 \pm 10 \%)$ e fotofase $(12 \mathrm{~h})$.

\begin{tabular}{lrrrr}
\hline İnstares & \multicolumn{2}{l}{ Consumo de ovos \pm Erro padrão } & Duração (dias) \pm Erro padrão & $\begin{array}{c}\text { Número de } \\
\text { Observações }\end{array}$ \\
\cline { 2 - 3 } & \multicolumn{1}{c}{ Diário } & \multicolumn{1}{c}{ Total } & & \\
\hline $1^{\circ}$ & $4,6 \pm 0,2$ & $39,0 \pm 2,6$ & $7,8 \pm 0,3$ & 65 \\
$2^{\circ}$ & $13,8 \pm 0,5$ & $115,8 \pm 4,3$ & $8,5 \pm 0,2$ & 65 \\
$3^{\circ}$ & $27,6 \pm 0,8$ & $216,7 \pm 6,7$ & $8,1 \pm 0,2$ & 65 \\
$4^{\circ}$ & $45,3 \pm 1,2$ & $434,5 \pm 13,1$ & $9,7 \pm 0,3$ & 65 \\
$5^{\circ}$ & $29,6 \pm 0,0$ & $444,0 \pm 0,0$ & $15,0 \pm 0,0$ & 1 \\
\hline
\end{tabular}

Durante a fase ninfal que foi de 34,4 dias, uma ninfa de tesourinha consumiu 23,7 ovos de $H$. zea por dia, perfazendo um consumo total nesta fase de 812,9 ovos/tesourinha. Já um adulto de tesourinha consumiu durante seu tempo de vida 7457,4 ovos (Tabela 3), resultando em um consumo diário de 42,1 ovos. Nota-se que o consumo diário médio nesta fase foi menor que o consumo diário de uma ninfa de quarto ínstar. Este menor consumo é explicado pelo rítmo de predação diária, que é, nos adultos, decrescente com a idade. Outra observação é a de que quando a fêmea faz postura, ela permanece sobre os ovos durante o período de incubação e nesta fase pôde-se observar que ela não se alimenta. 
Tabela 3. Consumo diário e total de Helicoverpa zea por ninfas e adultos de Doru luteipes, em laboratório, sob condições controladas de temperatura $\left(25 \pm 1^{\circ} \mathrm{C}\right)$, umidade relativa $(70 \pm$ $10 \%)$ e fotofase (12h).

\begin{tabular}{lccc}
\hline Fase & \multicolumn{2}{c}{ Consumo de ovos \pm Erro padrão } & \multirow{2}{*}{ Número de observações } \\
\cline { 2 - 3 } & Diário & Total & \\
\hline Ninfal & $23,7 \pm 0,4$ & $812,9 \pm 14,9$ & 65 \\
Adulto & $42,1 \pm 0,4$ & $7457,4 \pm 484,0$ & 38 \\
Total & $38,9 \pm 0,5$ & $8275,8 \pm 482,9$ & 38 \\
\hline
\end{tabular}

Nogeral, pode-se dizer que umatesourinha sealimenta durante sua vida de aproximadamente 8276 ovos de $H$. $z e a$, sendo 39 ovos/dia (Tabela 3). Isto justifica a importância do predador D. luteipes no controle da lagarta-da-espiga no milho, necessitando, entretanto, de estudos mais dirigidos à utilização do predador como um componente no manejo desta praga. Esse aspecto é muito importante pois a lagarta alimentando-se dentro da espiga além de reduzir a produtividade, reduz a qualidade do produto e sua capacidade de comercialização (Hoffmann et al. 1990). Nos Estados Unidos da América, por exemplo, onde o nível de dano é mínimo em milho doce, já que a qualidade cosmética do produto final é primordial, produtores chegam a aplicar inseticidas a cada 24 ou 48 horas, durante o período de liberação e maturação dos estilos-estígmas, onde encontram-se as lagartas de primeiros estágios, fase em que a praga é ainda passível de controle (Pitre et al. 1979). Mesmo assim o inseto causa prejuízos anuais que chegam a um bilhão de dólares, além do custo de mais de 250 milhões de dólares com a aplicação de inseticidas (King \& Coleman 1989). Considerando ainda que tentativas de utilização de medidas biológicas, como aplicações de Baculovirus por exemplo, não trazem grande eficiência, em função da dificuldade de aplicação no local onde a praga se localiza, ou seja na espiga do milho (Hamm \& Young 1971), o predador D. luteipes pode ser considerado como uma possibilidade real na supressão de $H$. zea na cultura do milho.

\section{LITERATURA CITADA}

Alvarenga, C.D. 1992. Controle integrado do pulgão-verde, Schizaphis graminum (Rondani, 1952) em sorgo através de genótipos resistentes e do predador Doru luteipes (Scudder, 1876). Dissertação de mestrado, ESALQ/USP, Piracicaba, 113p.

Alvarenga, C.D. \& I. Cruz. 1989. Viabilidade de controle do pulgão-verde, Schizaphis graminum (Rondani, 1852) (Homoptera: Aphididae) através de cultivares resistentes e do predador Doru luteipes (Scudder, 1876) (Dermaptera: Forficulidae), p.427. In Resumos Congresso Brasileiro de Entomologia, 12, Belo Horizonte, MG, 575p.

Brindle, A. 1971. A revision of the genus Doru Burr (Dermaptera: Forficulidae). Pap. Avul. Zool. 23: 173-196. 
Campos, A.R. \& S. Gravena. 1984. Inseticidas, Bacillus thuringiensis e artrópodos predadores no controle da lagarta da maçã no algodoeiro. An. Soc. Entomol. Birasil 13: 95105.

Cruz, I. 1990. Flutuação populacional do predador Doru luteipes, agente de controle biológico de Spodoptera frugiperda e Heliothiszea, p. 69. In Resumos Congresso Nacional de Milho e Sorgo, 18, Vitória, ES, 134p.

Cruz, I., J.M. Waquil, J.P. Santos, P.A. Viana \& L.O. Salgado. 1986. Pragas da cultura do milho em condições de campo. Métodos de controle e manuseio de defensivos. EMBRAPA/CNPMS, Circ. Téc. 10, 70p.

Hamm, J.J. \& J.R. Young. 1971. Value of virus presilk treatment for corn earworm and fall armyworm control in sweet corn. J. Econ. Entomol. 64: 144-146.

Hoffmann, M.P., L.T. Wilson, F.G. Zalom \& R.J. Hilton. 1990. Parasitism of Heliothis $z e a$ (Lepidoptera: Noctuidae) eggs: effect on pest management decision rules for processing tomatoes in the Sacrament Valley of California. Environ. Entomol. 19: 753-763.

Jones, R.W., F.E. Gilstrap \& K.L. Andrews. 1987. Activities and plant associations of the earwig, Doru taeniatum, in a crop-weed habitat. Southwest. Entomol. 12: 107-118.

King, E.G. \& R.J. Coleman. 1989. Potential for biological control of Heliothis species. Ann. Rev. Entomol. 34: 53-75.

Leite, L.G. \& F.M. Lara. 1985. Flutuação populacional de insetos e inimigos naturais associados à cultura da soja em Jaboticabal, SP. An. Soc. Entomol. Brasil 14: 45-57.

Lima, A.C. 1938. Insetos do Brasil. Rio de Janeiro, Escola Nacional de Agronomia. v. 1, 470p.

Painter, R.H. 1955. Insect on corn and teosinte in Guatemala. J. Econ. Entomol. 48: 36-42.

Pitre, H.N., W.J. Mistric \& C.G. Lincoln. 1979. Economic thresholds: concepts and techniques in: Economic threshold and sampling of Heliothis species on cotton, corn, soybeans and other host plants. Southern Cooperative Series. Bull. 231: 105-131.

Reis, L.L., L.J. Oliveira \& I. Cruz. 1988. Biologia e potencial de Doru luteipes no controle de Spodoptera frugiperda. Pesq. Agropec. Bras. 23: 333-342. 